\title{
The Transcendental and the Agonistic: A Media Philosophy Perspective
}

\author{
Timothy Barker ${ }^{1}$ \\ Published online: 10 April 2021 \\ (c) Crown 2021
}

\begin{abstract}
This critical response to Dominic Smith's 'Taking Exception: Philosophy of Technology as a Multidimensional Problem Space' begins by outlining the key contributions of his essay, namely his insightful approach to the transcendental, on the one hand, and his introduction of the topological problem space as an image for thought, on the other. The response then suggests ways of furthering this approach by addressing potential reservations about determinism. The response concludes by suggesting a way out of these questions of determinism by thinking the transcendental in concert with the agonistic.
\end{abstract}

Keywords Agonism · Technology and the transcendental $\cdot$ Mediation $\cdot$ Materialist media theory $\cdot$ Technological determinism $\cdot$ Media philosophy

Dominic Smith's essay provides a number of exciting questions for the philosophy of technology, none the least suggesting new images with which we should describe our practice of theory development and ideas of technological progress. The image of a road and the traveller moving along it, going through numerous turns, junctions, round-abouts, and entering and exiting cul de sacs, has been characteristic of a certain approach to technology that Smith wants to get beyond. As set out in the essay, he doesn't want us to think of technology with the image of a path leading to the future (of course we might stop on this road at some point, or might choose to diverge from it; but nevertheless, the image of the road is persistent). Instead he wants us to think of technology as providing a multidimensional problem space. Smith sets up this argument brilliantly with Heidegger and his image of 'building a way' as the general tendency to view theory development in terms of a series of 'turns' or 'crossroads,' which are then challenged quite insightfully by Smith. He tells us that new technologies do not simply build on old technologies, adding another mile to the highway. Instead, new technologies introduce new conditions, which are not directional but rather topological. Smith then asks us to consider a different image, one that in a sense is not representable directly and in fact resists depiction as an image. This is the

This comment refers to the article available at https://doi.org/10.1007/s10699-020-09735-4.

Timothy Barker

timothy.barker@glasgow.ac.uk

1 University of Glasgow, Gilmorehill Building, 9 University Avenue, Glasgow G128QQ, UK 
multi-dimensional image of the transcendental as a problem space; a space that does not completely organize and control the direction of travel but provides the conditions for possibility in the first place. So rather than building a track for thought that one must follow when thinking about the future of AI, for instance, if we turn attention to the transcendental we might see other possible lines of flight, other possible ways that this technology may develop, only limited by the topological invariants embedded in transcendental conditions. In this critical review I want to both highlight some of the key 'moves' that Smith makes and the contribution I can see in his work, but also try and suggest how this might be extended in two ways (1) by engaging with the spectre of determinism that might be associated with the transcendental and (2) by suggesting that the topic of the transcendental and Smith's work on problem spaces could be productively thought alongside agonism, struggle and difficulty.

Smith develops a number of insights in the essay as well as probes a number of already established paradigms in philosophy, particularly with respect to the transcendental. His essay provides a type of experimentation (as he puts it in the opening) in that he asks us to bring to mind a number of 'exceptional technologies' that then offer as a way to 'think through' (or experiment with) philosophical problems that can then be brought to bear on the everyday. In this sense, the 'exceptional' - those things that were never used as 'everyday' technologies, that have been superseded, that were marginalized, that never worked or that were forgotten - can, because of their exceptional status, offer new ways to think about the possibilities of technology, the possibilities of design of just what can be done with what is at hand. In this sense, looking at the 'exceptional' might equate to looking at the field of the possible, which is a good method to begin thinking about the transcendental as a field that conditions these possibilities. As Smith succinctly puts it, attention to the transcendental means looking "not merely to something considered "given" once and for all, but to the conditions of possibility under which it is given' (Smith, this issue) (i.e. the things that make discourse or experience or thought possible in the first place). From here, Smith then makes an argument that attention to the transcendental provides nothing less than a new image with which to think about technological development in general.

Smith's overview of the transcendental in philosophy is succinct and insightful and I need not restate all of that here. Suffice to say that his rendering of the transcendental as 'the set of formal conditions that necessarily and universally obtain prior to experience, and that make experience and knowledge possible' (Smith, this issue) is especially helpful when thinking the transcendental in association with technology. Of particular philosophical novelty is Smith's use of Kant against Kant, which in a sense 'opens up' his thought on the transcendental by attempting to do away with his anthropocentrism. These are significant moves for the philosophy of technology. But I would like to drill down a little deeper into what I see as being one persistent question that I had when it comes to thinking of the transcendental in tandem with technology and then one particular (possible) way of working a way out of this question. In full accord with Smith's essay, this would mean 'taking exception' in a positive, productive manner, designed at furthering the conversation, rather than obstructing it. As Smith rightly points out, his work provides a way to get beyond approaches to the transcendental that figure it as anything 'beyond' reality or 'out of this world.' But if we do this, if we locate the transcendental with real but not actual processes, does the transcendental become another name for invisible technical processes? And then, are we rehashing a type of deterministic argument? I am not sure that the answer to either of these questions is 'yes' (and certainly not to the second question). But it might be productive for Smith to explore these questions as opportunities to further the approach —or in fact to tell me if I've got it wrong! 
It might come as no surprise that, as someone that often takes an approach associated with media philosophy, my first instinct is to associate the transcendental with questions relating to levels of technicality and to the infrastructure of media systems that people like Kittler ([1986]1999), Krämer (2015), Ernst (2013) and Peters (2015) write about. My first instinct (which may I admit be 'off track') is to try and ground the transcendental in the real set of technical conditions upon which any mediation is based. Let's take television as an example: The images of the television, the dramas, comedies, news reports, political debates, sporting events, all involve multiple actors, agents, production companies, industry protocols, and so on, each with their own axe to grind. But prior to all of this is a media history of technical developments involving Nipkow disks, flickering lamps, selenium, Baird's televisor, the work of Marconi, EMI, Bell Labs amongst many others, as well as the development of the electronic binary computer. Although these things are completely invisible in the contemporary television image, they provide the set of conditions for the possibility of representation and hence the possibilities for television discourse. One example of this is the 'near seeing' associated with the television (an actor in close-up and a viewer sitting close to the screen, or-as is now more likely-holding the tablet screen close to their face). This is not something new but was a condition of the technological developments first made by Baird, where an actor had to remain close to the camera and the lights to be recognizable. In complete symmetry, at the other end of the transmission chain, the viewer had to remain close to the small screen in order to make out the picture (Zielinski [1989]1999, p. 187). Another example of the television, which is more relevant to Smith's arguments about exceptional technologies are the speculative inventions suggested by the magazine Television (Vol 1 No 1), as the medium was beginning to be developed. In a cartoon in the first issues in $1928,{ }^{1}$ multiple new uses for the still experimental technology of television are pictured, including the use by do-it-yourself barbers to view the back of their head on a tv screen, a teacher placing his students under surveillance while he takes a break, and a fisherman using an underwater camera to keep an eye on his bait, freeing him up to lie back in the boat, enjoy the sunshine and read a book. Can these be seen as an example of the technological imagination conditioned by the current state of the possible, as a multi-dimensional problem space? In these comics, images of one's own bodily capacities are extended, school pupils become subjects of surveillance, and leisure activities change based on technical capacities. As seen in these rather brief examples, perhaps attention to the technical processes is a way of linking the transcendental and the empirical, to the conditions for what is possible? Perhaps this is what's needed to further trivialize the transcendental and resist common misconception of it 'above' or 'beyond' existence?

Of course, this line of thinking may draw the same criticism leveled at technological determinism. After all, it is humans that design the technology, not the other way around. If we look to conditions rather than those things that emerge from the conditions, are we looking the wrong way? Can we really hope to get where technology is 'coming from' if we stop thinking so much about where it 'is going to'? My answer would of course be that attention to conditions certainly does not equate to technological determinism, though I could understand this as a reservation that some readers may have. But there is a spectrum between complete determinism and complete freedom of expression. As Latour (2005, pp.

\footnotetext{
${ }^{1}$ The magazine can be accessed on the National Science and Media Museum online archive here: https:// collection.sciencemuseumgroup.org.uk/objects/co34420/volume-1-no-1-of-television-monthly-magazine1928-publication.
} 
71-72) points out, the hammer does not 'impose' the hitting of the nail, the basket does not 'cause' the gathering of food. Instead there are many shades of causality between a full technological determinism and inexistence. 'In addition to "determining" and serving as a "back-drop for human action," things might authorize, allow, afford, encourage, permit, suggest, influence, block, render possible, forbid and so on' (Latour 2005, p. 72). Now Latour is talking about 'things' in the above passage (hammers, baskets and so on), but we could equally use this as a way to talk about, as Smith does, the conditions that processually articulate themselves to the production of things.

One of the most infamous figures around in terms of technological determinism is perhaps Kittler, who ([1986]1999), in a trademark provocative tone, said in the infamous opening to Gramophone, Film, Typewriter that 'media determine our situation' (p. xxxix). But this is not, as many have read it, about the possibility of technological determinism. It is about the way media, because of their time-based processing routines, determine the possibility to represent events in discourse, and thus determine the way these events come to define a situation. This, to me, may be something to contribute to those things set out in Smith's essay. It may be that attention to the transcendental suggests an exploration of these technical affordances. What's more, a productive way to think through this problem space may come with the help of the topic of agonism, of difficulty, of competition and of play-each of which presupposes a set of conditions as a problem space. It may be that agonism lets us talk about play within a set of transcendental conditions, rather than picturing the transcendental as a set of condition that determine action.

Smith does indeed gesture towards the agonistic, none the least with the example of design developed through his reading of Floridi's example of the chess player. Perhaps it is agonism, struggle, the competition against conditions, that is at stake in Smith's thinking? (After all there is a lot about games in there already.) In particular, Smith gives us Floridi's example of the philosopher as a designer, as a figure who creatively designs solutions to a problem. I would like to slightly reword this as someone who creatively struggles with, agonizes over, a problem, rather than 'solves' or provides 'solutions.' This, it seems, would be a more playful way to think about problems and the drive to thought. But this is a specific type of playfulness as a process that is directed at better getting to know the rules of the system. And it is also more than this. Rather than playing the game to only learn the rules and subsequently learn how to play within the rules, the agonisitic suggests a type of struggle within and sometimes against the rules - a type of individuation that involves neither the rules (conditions/transcendental) nor the player (as subject) alone.

The agonistic might offer a way to think through the sites of resistance to the conditions provided by technology. In Smith's final example, using Morton to describe a friendly/notfriendly encounter in a parking lot, he hints at this struggle: "every turn, whether ostensibly "towards" or "away," has implications in multiple different directions at once. How are these two strangers meant to get at the range of complex issues implied by the parking lot, their cars, the supermarket, and one another, at once?' (Smith, this issue). The parking lot is the space for struggle, it is the space for agonism, a space, as Smith puts it, off road.

Open Access This article is licensed under a Creative Commons Attribution 4.0 International License, which permits use, sharing, adaptation, distribution and reproduction in any medium or format, as long as you give appropriate credit to the original author(s) and the source, provide a link to the Creative Commons licence, and indicate if changes were made. The images or other third party material in this article are included in the article's Creative Commons licence, unless indicated otherwise in a credit line to the material. If material is not included in the article's Creative Commons licence and your intended use is not 
permitted by statutory regulation or exceeds the permitted use, you will need to obtain permission directly from the copyright holder. To view a copy of this licence, visit http://creativecommons.org/licenses/by/4.0/.

\section{References}

Ernst, W. (2013). Digital memory and the archive. Minneapolis: University of Minnesota Press.

Kittler, F. ([1986]1999). Gramophone, film, typewriter (trans: Winthrop-Young, G., Wutz, M.). Stanford, CA: Stanford University Press.

Krämer, S. (2015). Media, messenger, transmission: An approach to media philosophy (trans: Enns, A.). Amsterdam: Amsterdam University Press.

Latour, B. (2005). Reassembling the social: An introduction to actor-network-theory. Oxford: Oxford University Press.

Peters, J. D. (2015). The marvelous clouds: Towards a philosophy of elemental media. Chicago: University of Chicago Press.

Zielinski, S. ([1989]1999). Audiovisions: Cinema and television as entr'actes in history (trans: Custance, G.). Amsterdam: Amsterdam University Press.

Publisher's Note Springer Nature remains neutral with regard to jurisdictional claims in published maps and institutional affiliations.

Timothy Barker is Professor of Media Technology and Aesthetics in the School of Culture and Creative Arts at the University of Glasgow. His work focuses on media and the philosophy of time from both aesthetic and historical perspectives, which can be seen respectively in his two books: Time and the Digital (Dartmouth, 2012) and Against Transmission (Bloomsbury, 2018). In these books, along with other essays on the topic, he explores media forms such as experimental television, digital art, video games, cinema, and photography based on what they can tell us about the cultural representations and operations of memory, history and temporality. 